\title{
Inclusion Evolution Behavior of Ti-Mg Oxide Metallurgy Steel and Its Effect on a High Heat Input Welding HAZ
}

\author{
Hao-Nan Lou ${ }^{1}$, Chao Wang ${ }^{1}$, Bing-Xing Wang ${ }^{1, *}$, Zhao-Dong Wang ${ }^{1}$, Yu-Qian Li ${ }^{2}$ \\ and Zi-Gang Chen ${ }^{2}$ \\ 1 State Key Laboratory of Rolling and Automation, Northeastern University, NO. 3-11, Wenhua Road, \\ Heping District, Shenyang 110819, Liaoning, China; 13555813046@163.com (H.-N.L.); \\ chao_neu@163.com (C.W.); zhdwang@mail.neu.edu.cn (Z.-D.W.) \\ 2 Handan Iron \& Steel Group Co., Ltd., No. 232, Fuxing Road, Fuxing Distirct, Handan 056015, Hebei, China; \\ liyuqian@hbisco.com (Y.-Q.L.); chenzigang@hbisco.com (Z.-G.C.) \\ * Correspondence: wbxang@126.com; Tel.: +86-024-8368-1190
}

Received: 6 June 2018; Accepted: 9 July 2018; Published: 11 July 2018

\begin{abstract}
We have studied here the evolution of inclusions in ladle furnace (LF), Ruhrstahl \& Heraeus furnace $(\mathrm{RH})$, and simulated welded samples during Ti-Mg oxide metallurgy treatment and the mechanical properties of the heat-affected zone (HAZ) after high heat input welding. The study indicated that inclusions in an LF furnace station are silicomanganate and MnS of size range $\sim 0.8-1.0 \mu \mathrm{m}$. After Mg addition, fine Ti-Ca-Mg-O-MnS complex oxides were obtained, which were conducive to the nucleation of acicular ferrite (AF). The corresponding microstructure changed from ferrite side plate (FSP) and polygonal ferrite (PF) to AF, $\mathrm{PF}$, and grain boundary ferrite (GBF). After a simulated welding thermal cycle of $200 \mathrm{~kJ} / \mathrm{cm}$, disordered arrangements of acicular ferrite plates, fine size cleavage facets, small inclusions, and dimples all promoted high impact toughness.
\end{abstract}

Keywords: Ti-Mg oxide metallurgy; inclusion; microstructure; heat-affected zone

\section{Introduction}

During the steel-making process, clean steel is the main objective and inclusions are harmful to steel properties, such as toughness and strength [1,2]. However, with deep understanding, the concept of "oxide metallurgy" was proposed, where fine non-metallic inclusions are used to pin the grain boundaries and promote intragranular acicular ferrite (AF) transformation for enhancing the toughness of the heat-affected zone (HAZ).

In order to realize the optimum efficiency of oxide metallurgy, the process of steel making needs to be carefully controlled [3,4]. For high-strength, low-alloy steels, many researchers found that certain types of fine oxide inclusions with a high melting point could increase the toughness of the HAZ after high heat input welding [5-7]. Ti-containing oxides are well-known to act as nucleation sites for acicular ferrite, which can divide large austenite grains into many finer and separate areas consisting of a fine-grained microstructure [8-10]. Zhu et al. [11] found that the toughness of the HAZ in Ti-bearing low-carbon steels was improved by adding $0.005 \mathrm{wt} \% \mathrm{Mg}$. Xu et al. [12] studied the effect of $\mathrm{Mg}$ content on the toughness and microstructure of the HAZ after high heat input welding and found that with the increase of $\mathrm{Mg}$ content from 0 to $0.0099 \mathrm{wt} \%$, the major microstructure in the HAZ changed from ferrite side plate (FSP), upper bainite (Bu), and grain boundary ferrite (GBF) to AF with the austenite size decreased from $437 \mu \mathrm{m}$ to $122 \mu \mathrm{m}$. Miia et al. [13] reported the evolution during cooling of different types of Ti-oxide in C-Mn-Cr steel. Wang et al. [5] investigated the transformation behavior in Ti-Zr deoxidized steel. Besides the composition of inclusions, size is also an important factor: tough, 
large inclusions are harmful to mechanical properties. Entrapped inclusions can lead to internal cracks, blisters, and slivers in the rolled plates or during subsequent working operations [14].

Although a number of studies have investigated the properties of the HAZ, few studies have focused on the evolution behavior during the steel-making process. In this study, we present the composition, morphology, average size, and number density of inclusions in Ti-Mg-treated EH420 ship-building steel. The properties of the HAZ after thermal welding simulations are also explored.

\section{Materials and Methods}

The chemical composition of plain EH420 and EH420-Mg with Ti-Mg treatment is shown in Table 1. The production steps were: Si-Mn pre-deoxidation $\rightarrow$ ladle furnace (LF) refining $\rightarrow$ vacuum treatment in Ruhrstahl \& Heraeus furnace (RH) $\rightarrow$ continuous casting. For EH420-Mg steel, in the step of LF refining, Ti-Fe, Ni-Mg alloy, and Nb-Fe were sequentially added. EH420 steel was used only for toughness comparison after the thermal welding simulation. The sampling positions of EH420-Mg were the LF furnace station, Ti-Mg treatment in the LF furnace, and vacuum treatment in the $\mathrm{RH}$ furnace, respectively. After casting, the ingots were both reheated to $1100^{\circ} \mathrm{C}$ for $2 \mathrm{~h}$ and rolled into $30-\mathrm{mm}$ plate by thermo-mechanically controlled processing (TMCP) with a cooling rate of $32{ }^{\circ} \mathrm{C} / \mathrm{s}$ and a final cooling temperature of $570^{\circ} \mathrm{C}$.

Table 1. Chemical composition of experimental steel in wt \%.

\begin{tabular}{ccccccccccccc}
\hline Steel & $\mathbf{C}$ & $\mathbf{S i}$ & $\mathbf{M n}$ & $\mathbf{S}$ & $\mathbf{P}$ & $\mathbf{T i}$ & $\mathbf{C a}$ & $\mathbf{N b}$ & $\mathbf{M g}$ & $\mathbf{N i}$ & $\mathbf{O}$ & $\mathbf{N}$ \\
\hline EH420 & 0.06 & 0.12 & 1.53 & 0.008 & 0.008 & 0.015 & 0.003 & 0.014 & - & 0.28 & 0.005 & 0.005 \\
EH420-Mg & 0.07 & 0.12 & 1.65 & 0.006 & 0.005 & 0.013 & 0.003 & 0.015 & 0.003 & 0.3 & 0.003 & 0.005 \\
\hline
\end{tabular}

In order to compare the ability of AF nucleation by different types of inclusions and the change in microstructure from the LF furnace to the RH furnace, samples from a steel shop were machined to $3 \mathrm{~mm}$ in diameter and $10 \mathrm{~mm}$ in length for a continuous cooling transformation with Formastor-FII full-automatic transformation equipment. The specimens were heated to $1250{ }^{\circ} \mathrm{C}$ and held for $3 \mathrm{~min}$ then cooled at a rate of $20^{\circ} \mathrm{C} / \mathrm{s}$ to $570{ }^{\circ} \mathrm{C}$ and $5{ }^{\circ} \mathrm{C} / \mathrm{s}$ to room temperature. To simulate welding, specimens from the EH420 and EH420-Mg were cut from the hot-rolled steel plate and machined into $11 \times 11 \times 55 \mathrm{~mm}^{3}$ for HAZ simulation using an MMS 300 machine (RAL, NEU, Shenyang, China), Rykalin 2D equipped with a welding software package. The peak temperature was $1400{ }^{\circ} \mathrm{C}$ with a heating rate of $100{ }^{\circ} \mathrm{C} / \mathrm{s}$ and held for $2 \mathrm{~s}$. The targeted heat input was estimated to be $200 \mathrm{~kJ} / \mathrm{cm}$. After the welding simulation, the specimens were machined to dimensions of $10 \times 10 \times 55 \mathrm{~mm}^{3}$ for a Charpy v-notch impact test at $-20^{\circ} \mathrm{C}$.

After the test by a dilatometer and the thermal welding simulation, samples of EH420-Mg were etched with $4 \%$ nital and their microstructure was observed by optical microscope. The fracture surface of the impact test was examined using a scanning electron microscope (SEM), and the inclusions of each sample were analyzed via SEM equipped with an inclusion automatic analysis system and an energy dispersive spectrometer (EDS). In order to ensure the reliability of the EDS analysis, each sample was scanned and a large area $\left(1.217 \mathrm{~mm}^{2}\right)$ for EDS analysis at high magnification $(3000 \times)$ was used. On the other hand, the EDS analysis was employed to exclude the possibility that pores and blots would be misunderstood as inclusions.

\section{Results and Discussion}

\subsection{Evolution of Inclusions in EH420-Mg}

The shape and composition of inclusions (atomic percentage) of each position are shown in Figure 1. The inclusions were mainly spherical. In Figure 1a (LF furnace station), it can be seen that the content of Mn was higher than that of S, which suggested that Mn did not exist in the form of a sulfide and consisted of silicomanganate and MnS. After Ti-Mg treatment in the LF furnace, the inclusions 
were Ti-Mg-O complex oxides and MnS precipitates. Nucleation of AF plates induced by inclusions was found, but individual $\mathrm{MgO}$ inclusions were not observed; Chai et al. [15] reported that $\mathrm{MgO}$ can be observed only when the content of $\mathrm{Mg}$ is $\sim 60 \mathrm{ppm}$. On the other hand, $\mathrm{Mg}$-containing inclusions easily float and the gasification of $\mathrm{Mg}$ and $\mathrm{TiOx}$ reduced by $\mathrm{Mg}$ can also lower the content. In the sample of vacuum treatment in the $\mathrm{RH}$ furnace, the inclusions in the core were mainly Ti-Ca- $\mathrm{Mg}-\mathrm{O}$ because a reducing slag containing $\mathrm{CaO}$ was formed before the $\mathrm{RH}$ furnace and reduction reaction. Thus, the content of $\mathrm{Ti}$ and $\mathrm{Mg}$ was decreased.
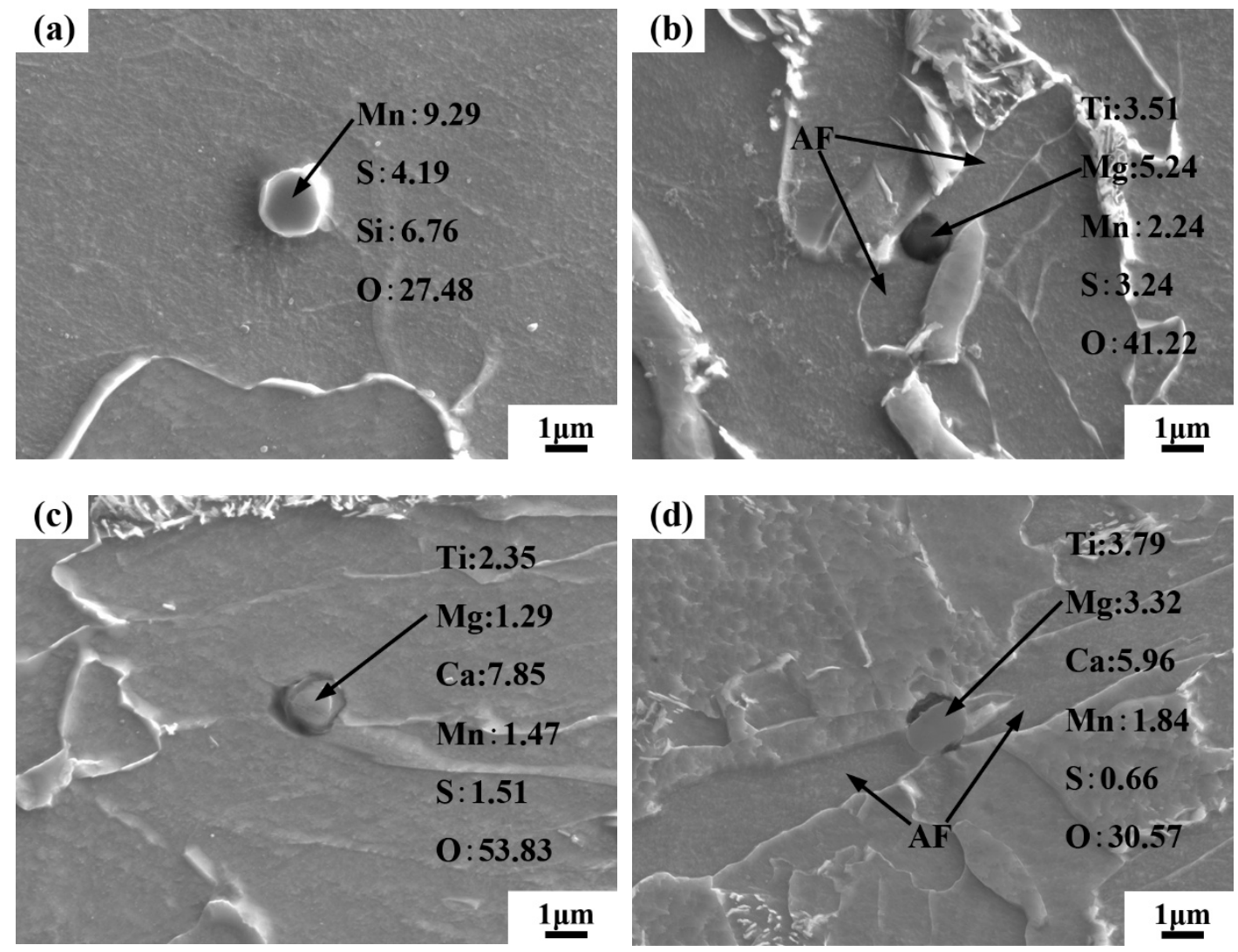

Figure 1. Evolution of typical inclusions about shape and composition.(a) ladle furnace (LF) station; (b) Ti-Mg treatment in the LF furnace; (c) vacuum treatment in the Ruhrstahl \& Heraeus furnace (RH); (d) after the thermal welding simulation.

Figure $1 \mathrm{~d}$ shows inclusions consisting of Ti-Ca-Mg-O oxides in the core and MnS precipitation on the surface in the welded sample. After continuous casting, the solidification structure in Fe- $10 \%$ $\mathrm{Ni}$ alloy deoxidized by $\mathrm{Mg}$ was studied [16] and the results showed that columnar dendrites grew from grain boundaries into a columnar dendrite zone and the interdendritic spacing was decreased. Holappa et al. [17] observed that $\mathrm{Mn}$ and S were affluent in an interdendritic melt. Thus, Mg addition decreases interdendritic spacing and increases the segregation of $\mathrm{Mn}$ and $\mathrm{S}$ to promote precipitation of MnS. However, during the heating process of the thermal welding simulation, the solubility of $\mathrm{Mn}$ and S was increased and showed a favorable diffusivity [18]. A inclusion with a large interfacial area can promote multiple nucleations of $\mathrm{MnS}$ on its surface [19]. In addition, it was reported that Ti-Mg-containing oxides can partition Mn into inclusions according to the results of first principle calculation [20]. Hence, individual MnS inclusions were barely observed and precipitated on the surface of Ti-Ca-Mg-O oxides.

The statistical result of size distribution and number density (an intensive quantity used to describe the degree of concentration of particles in $1 \mathrm{~mm}^{2}$ ) in samples is shown in Figure 2. The number density of inclusions was 1508, 1320,874, and $591 / \mathrm{mm}^{2}$, and the average size was $0.83,0.6,0.47$, 
and $1.67 \mu \mathrm{m}$, respectively. In Figure 1a, the size of inclusions was mainly in the range of $0.8-1.0 \mu \mathrm{m}$. In this range, due to the high oxygen content, some coarse inclusions of 2.0-5.0 $\mu \mathrm{m}$ were observed. After Ti-Mg treatment in the LF furnace, the number density of coarse inclusions was decreased due to collisions and a number of fine inclusions containing $\mathrm{Mg}$ were formed.

The formation of inclusions can be divided into three stages: nucleation, growth, and Ostwald ripening [14]. In the beginning, inclusions mainly depend on the degree of supersaturation (S), the interfacial energy between inclusions and molten steel $(\gamma)$, and the concentration product of the deoxidation equilibrium. The concentration product between $\mathrm{Ti} / \mathrm{Mg}$ and $\mathrm{O}$ increases with time and the inclusions start to nucleate when critical supersaturation (CS) is achieved. Subsequently, $\mathrm{S}$ will decrease with the reaction of deoxidation and the process of nucleation ends when CS is again achieved. Prior to the balance of $S=1$, the diffusion of particles will cease and Ostwald ripening occurs. If the value of $S$ is lower and $\gamma$ is higher, it is difficult for inclusions to nucleate and the areal density decreases. However, after feeding Ni-Mg alloy wires, the content of $\mathrm{Mg}$ and $\mathrm{O}$ in the LF furnace was $0.01 \%$ and $0.006 \%$, respectively, and $\mathrm{S}_{[\mathrm{Mg}][\mathrm{O}]}$ was high enough at $1600{ }^{\circ} \mathrm{C}$ to form fine and dispersed inclusions. Thus, this is the most important aspect of oxide metallurgy.

Vacuum treatment in an RH furnace reduces the number density of inclusions, but on the addition of Ca-containing cored wires, fine inclusions were formed, and the average size was refined to $0.47 \mu \mathrm{m}$. During the process of steel making, without considering the effect of collision and diffusion, inclusions grow following the theory of Lifshitz, Slyozov, and Wagner (LSW) [21,22]. At time $t$, the radius of an inclusion is related to the oxygen concentration and time, and because there is enough time for inclusions to grow, the oxygen concentration needs to be controlled to prevent coarsening. After the thermal welding simulation, the size distribution of inclusions in the EH420-Mg experienced a significant change. At a high temperature, oxides are partially dissolved and partial ripening occurs such that the number of inclusions of size range $\sim 1-5 \mu \mathrm{m}$ increases and those of less than $0.4 \mu \mathrm{m}$ disappear.
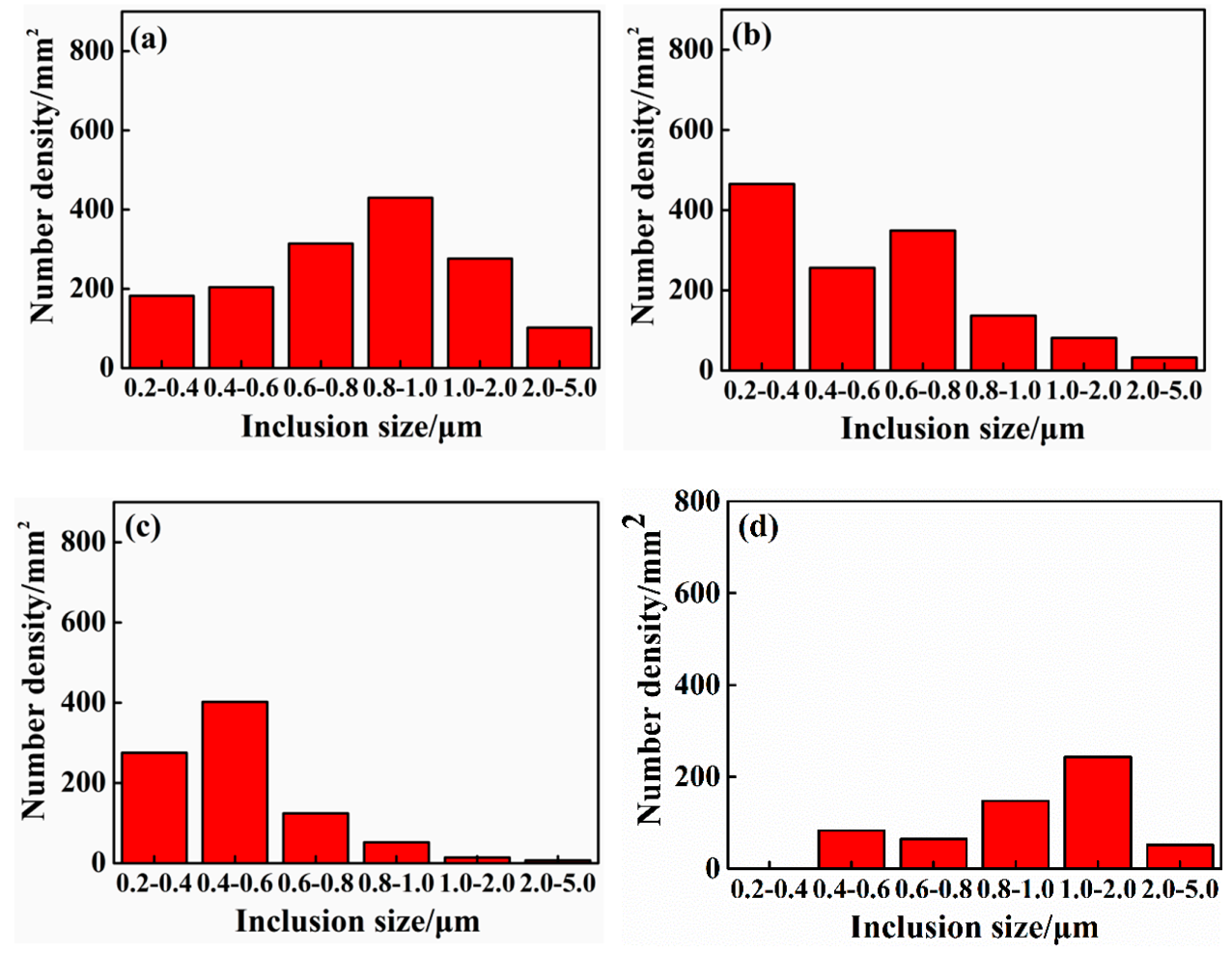

Figure 2. Size distribution, average size, and number density of inclusions in EH420-Mg: (a) LF furnace station; (b) Ti-Mg treatment in the LF furnace; (c) vacuum treatment in the RH furnace; (d) after the thermal welding simulation. 


\subsection{Evolution of Microstructure in EH420-Mg}

The microstructure at every sampling position from the steel shop after a thermal cycle by a dilatometer was observed and is shown in Figure 3. The microstructure in the LF furnace station was mainly composed of FSP and polygonal ferrite (PF) as shown in Figure 3a. It can be seen that oxides by Si-Mn deoxidation cannot induce nucleation of AF. Figure $3 b$ shows the microstructure after Ti-Mg treatment in the LF furnace. The microstructure consisted of GBF, PF, and AF. FSP was also observed but the volume fraction was less. These results indicated that (Ti-Mg-O) oxides introduced by oxide metallurgy in an LF furnace can provide effective nucleation sites for AF. Figure 3c shows the microstructure after vacuum treatment in the RH furnace. Compared with the sample in the LF furnace, $\mathrm{Nb}$-Fe alloy was added in the LF furnace and $\mathrm{Nb}$ can enhance the hardenability of steel [23]. On the other hand, a higher number density of Ca-containing inclusions was formed and the formation of AF was promoted [24]. The microstructure was composed of AF, PF, and B. In Figure 3d, the microstructure is composed of a high volume fraction of AF inside the grains and a small block of GBF and PF, and the grain size was $\sim 170 \mu \mathrm{m}$. The addition of $\mathrm{Mg}$ pinned the growth of grains effectively during the process of the welding thermal cycle.
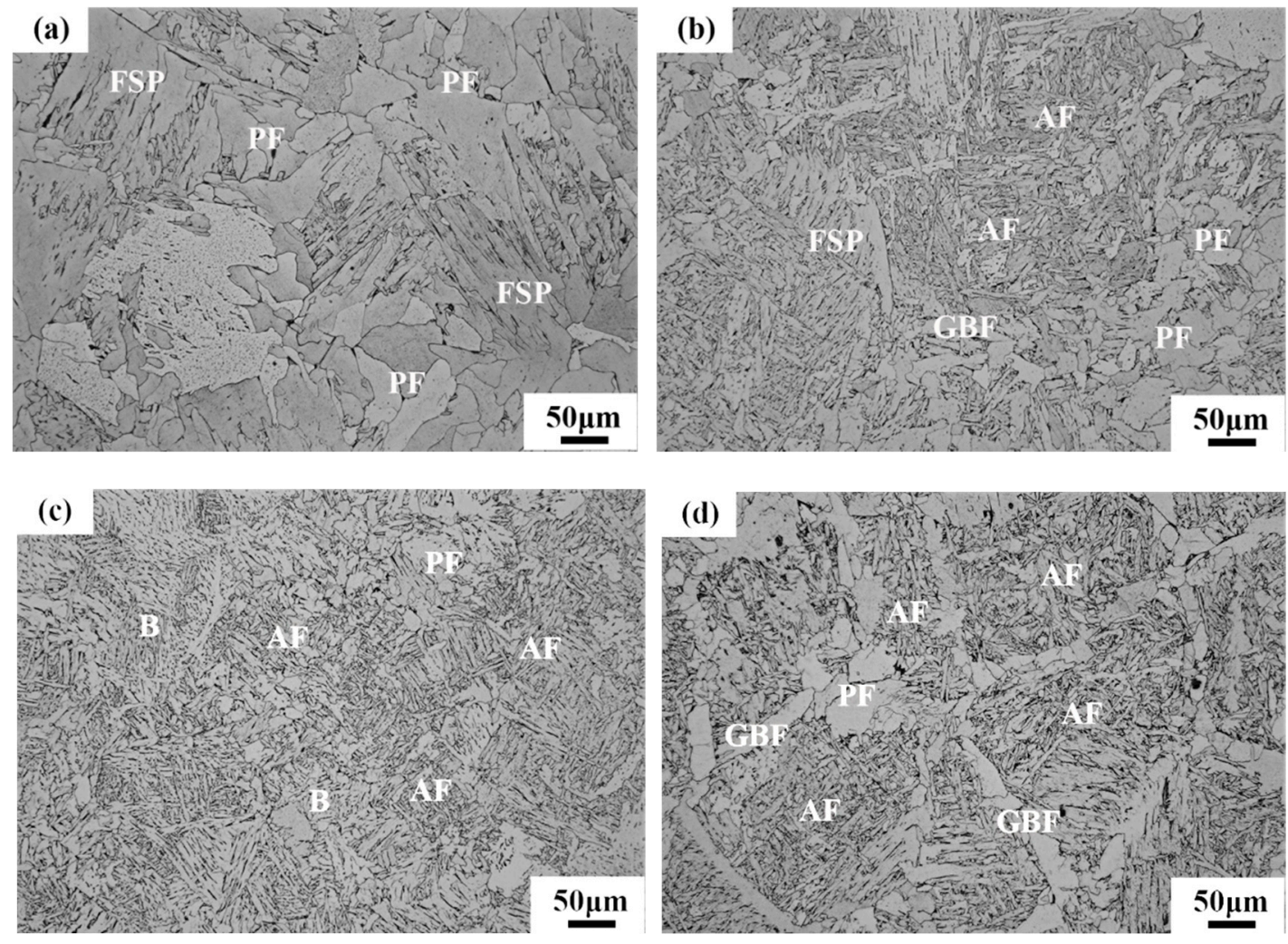

Figure 3. Evolution of microstructure in EH420-Mg: (a) the LF furnace station; (b) Ti-Mg treatment in the LF furnace; (c) vacuum treatment in the RH furnace; (d) after the thermal welding simulation. AF, acicular ferrite; PF, polygonal ferrite; GBF, grain boundary ferrite; FSP, ferrite side plate; B, bainite.

There are several mechanisms that explain the nucleation of AF: (1) the solute depletion in the vicinity of non-metallic inclusions [25-28]; (2) thermal strain energy due to a different thermal contraction [29]; (3) reduced interfacial energy between austenite and ferrite [30]; and (4) provision of an inert surface [31]. The most accepted explanation is that an Mn-depleted zone (MDZ) can be formed around Ti-containing oxides. An MDZ is formed because of the difference between the diffusivity of $\mathrm{Mn}$ in austenite and the solubility of $\mathrm{Mn}$ in $\mathrm{Ti}_{2} \mathrm{O}_{3}$, which lowers the content of Mn around 
the inclusion as compared to the matrix. Thus, the AF nucleation was promoted during the $\gamma \rightarrow \alpha$ phase transformation.

Besides the chemistry of inclusions, size is an important factor in oxide metallurgy. The results of Lee et al. [31] showed that the ability for AF nucleation increased with inclusion size up to $1 \mu \mathrm{m}$. Thus, there is a need to control the size of inclusions. With the treatment of $\mathrm{Ti}$ and $\mathrm{Mg}$, a number of inclusions are generated. When the peak temperature is $1400^{\circ} \mathrm{C}$, inclusions, such as TiN, will grow up and dissolve [32] in austenite; hence, the pinning effect is weakened and leads to the growth of grains. In order to predict the size of austenite grains, Zener's model in Equation (1) [33] expresses the pinning effect of particles on the movement of grain boundaries.

$$
R=A \times \frac{r}{f}
$$

where $R$ is the radius of a grain; $A$ is a constant depending on the geometry and force balance; $r$ is the radius of the second-phase particles; and $f$ is the volume fraction of second-phase particles.

According to Equation (1), a fine size with a high volume fraction can restrict the growth of grains effectively, because $\mathrm{Mg}$ is a strong deoxidizing element and even a small amount of addition in steel can form many oxide inclusions and they tend to be dispersed [34]. Thus, Mg-containing oxides can inhibit the growth of grains and induce the nucleation of AF.

\subsection{Effect of Inclusions on the HAZ after High Heat Input Welding}

In order to compare the mechanical properties of the HAZ after Ti-Mg treatment with plain EH420, Charpy impact tests were carried out. Table 2 shows the impact toughness values and the area fraction of the fracture surface. The average impact toughness at $-20^{\circ} \mathrm{C}$ of specimens $\mathrm{EH} 420$ and $\mathrm{EH} 420 \mathrm{Mg}$ was 168 and $262 \mathrm{~J}$, respectively. The EH420-Mg steel showed excellent HAZ toughness because the fibrous zone and the shear leap zone was $44.3 \%$ and $33.5 \%$, respectively.

Table 2. Statistical analysis of fracture surface and impact toughness of $\mathrm{HAZ}$ at $-20^{\circ} \mathrm{C}$.

\begin{tabular}{|c|c|c|c|c|c|c|c|}
\hline \multirow{2}{*}{ Steel } & \multicolumn{3}{|c|}{ Impact Fracture } & \multicolumn{4}{|c|}{ Impact Toughness (J) } \\
\hline & Fibrous Zone (pct) & Radical Zone (pct) & Shear Lip Zone (pct) & & dual & ue & Mean \\
\hline EH420 & 34.6 & 35.6 & 29.8 & 176 & 157 & 170 & 168 \\
\hline EH420-Mg & 44.3 & 22.2 & 33.5 & 252 & 264 & 271 & 262 \\
\hline
\end{tabular}

Figure 4 shows the SEM images and an optical micrograph of the microstructure adjacent to the fracture surface after a $200 \mathrm{~kJ} / \mathrm{cm}$ simulated HAZ for the two steels. As shown in Figure $4 \mathrm{a}, \mathrm{b}$, the cleavage plane was rough and the cleavage plane size was related to the size of the ferrite packet. The large cleavage plane provides a path for crack cleavage resulting in a decrease of the toughness of the HAZ. Figure $4 \mathrm{c}$ shows that the fracture surface was composed of brittle cleavage and a ductile fracture. Compared with plain EH420, the size of the cleavage was small (Figure 4d). It is known that the cleavage plane is related to grain size, and fine size cleavage facets can cause crack deflection frequently; thus, the driving force for crack propagation is decreased and toughness enhanced.

In fact, the crystallographic packet [35], which is defined as a group of adjacent ferrite laths with a crystallographic misorientation of less than $15^{\circ}$ of the critical angle, is the real microstructural unit that controls the propagation of cleavage cracks [36,37]. When the misorientation angle of crystallographic packets' boundaries is $15^{\circ}$ or higher, it is equivalent to the dimensions of the cleavage plane and fine-grained interlocking plates can lead to the division of a crack path or frequent deflection, preventing the propagation of cracks. 

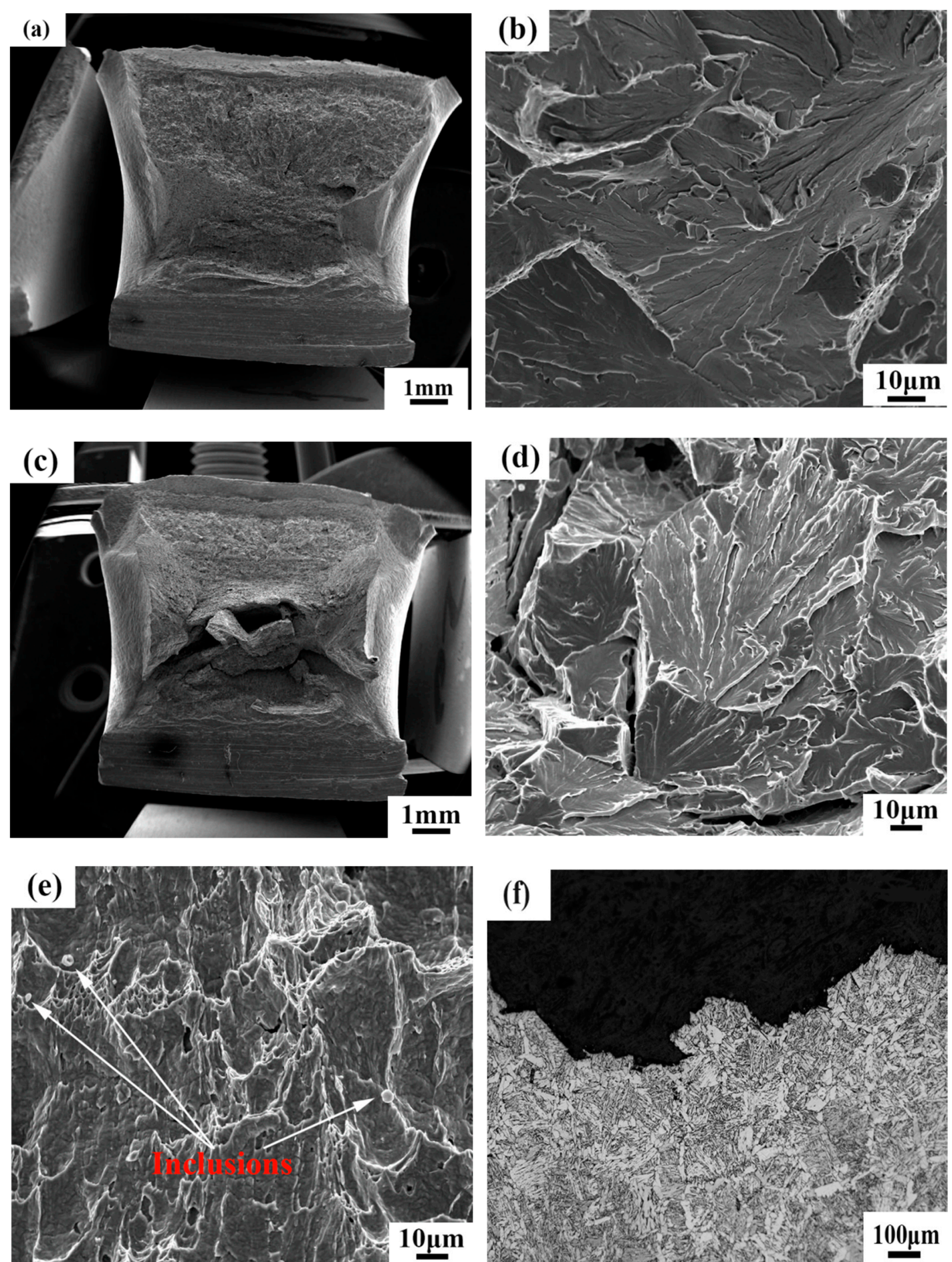

Figure 4. SEM images of the fracture surface and the microstructure adjacent to the fracture surface in (a,b) plain EH420; and (c-f) EH420-Mg.

The ductile fracture zone is shown in Figure 4e, which made a prominent contribution to the impact toughness. The spherical inclusions were embedded in dimples, and these inclusions with appropriate diameters can reduce the stress concentration [11]. During the plastic deformation process, the randomly distributed ferrite plates or grains were deformed and rotated to form sheaves with a similar orientation. It is inferred that the ductile fracture occurred as follows: the large size dimples are related to inclusions and are influenced by the size of inclusions. Small dimples are generated 
by fine inclusions, but they are more likely to be formed by the tearing of deformed ferrite sheaves. During the crack nucleation and growth process, inclusions were first separated from the surrounding matrix to form large-size dimples. Subsequently, the ferrite sheaves in the matrix around the dimples experienced axial tension, the final fracture under the stress concentration occurred, and dense fine dimples were observed in the cross section of several ferrite plates [5]. Figure 4e shows that the disordered lath arrangement of AF acted as an obstacle to the propagation of cleavage cracks. Fine-size cleavage facets and a dimpled ductile fracture contributed to the high impact energy.

\section{Conclusions}

1. The composition of inclusions in the core changed from silicomanganate and MnS (LF furnace station) to Ti-Mg-O (Ti-Mg treatment in the LF furnace) and finally to Ti-Ca-Mg-O in EH420-Mg. The corresponding average size of inclusions decreased from $0.83 \mu \mathrm{m}$ to $0.47 \mu \mathrm{m}$, and the number density decreased from $1508 / \mathrm{mm}^{2}$ to $874 / \mathrm{mm}^{2}$. After the thermal welding simulation, the inclusions of size less than $0.4 \mu \mathrm{m}$ disappeared.

2. For EH420-Mg steel, after a continuous cooling transformation by a dilatometer, the microstructure of the LF furnace station sample was composed of FSP and PF, which then changed to AF, PF, and B (vacuum treatment in an RH furnace), while in the welded sample, the microstructure was composed of AF, GBF, and PF. A Ti-Mg-containing oxide promoted the nucleation of AF.

3. An interlocking AF microstructure acts as an obstacle to the propagation of cleavage cracks. Fine-size cleavage facets, small inclusions, and dense dimples contributed to the high impact toughness in Ti-Mg oxide metallurgy steel.

Author Contributions: H.-N.L., C.W., B.-X.W. and Z.-D.W. conceived and designed the experiments; H.-N.L. performed the experiments; H.-N.L. and C.W. analyzed the data; Y.-Q.L. and Z.-G.C. contributed reagents/materials/analysis tools; H.-N.L. wrote the paper.

Funding: This work was financially supported by the National Key Research and Development Program of China (No. 2016YFB0300602).

Acknowledgments: R.D.K. Misra gratefully acknowledges the continued collaboration with Northeastern University as an honorary professor by providing guidance to students in research.

Conflicts of Interest: The authors declare no conflict of interest.

\section{References}

1. Garrison, W.M.; Wojcieszynski, A.L. A discussion of the effect of inclusion volume fraction on the toughness of steel. Mater. Sci. Eng. A 2007, 464, 321-329. [CrossRef]

2. Faulring, G.M.; Ramalingam, S. Oxide inclusions and tool wear in maching. Metall. Trans. A 1979, 10, 1781-1788. [CrossRef]

3. Sawai, T.; Wakoh, M.; Ueshima, Y.; Mizoguchi, S. Analysis of oxide dispersion during solidification in Ti, Zr-deoxidized steels. ISIJ Int. 1992, 32, 169-173. [CrossRef]

4. Ma, Z.T.; Janke, D. Oxide metallurgy-its purposes and practical approaches. Acta Metall. 1998, 22, 79-86.

5. Wang, C.; Misra, R.D.K.; Shi, M.H.; Zhang, P.Y.; Wang, Z.D.; Zhu, F.X.; Wang, G.D. Transformation behavior of a Ti-Zr deoxidized steel: microstructure and toughness of simulated coarse grain heat affected zone. Mater. Sci. Eng. A 2014, 594, 218-228. [CrossRef]

6. Suito, H.; Vladimirovich, K.A.; Hamada, M.; Inoue, R.; Nakajima, K. Influence of oxide particles and residual elements on microstructure and toughness in the heat-affected zone of low-carbon steel deoxidized with Ti and Zr. ISIJ Int. 2011, 51, 1151-1162. [CrossRef]

7. Kim, B.; Uhm, S.; Lee, C.; Lee, J.; An, Y. Effects of inclusions and microstructures on impact energy of high heat-input submerged-arc-weld metals. J. Eng. Mater. Technol. 2005, 127, 204-213. [CrossRef]

8. Wan, X.L.; Wei, R.; Wu, K.M. Effect of acicular ferrite formation on grain refinement in the coarse-grained region of heat-affected zone. Mater. Charact. 2010, 61, 726-731. [CrossRef] 
9. Wan, X.L.; Wu, K.M.; Huang, G.; Wei, R.; Cheng, L. In situ observation of austenite grain growth behavior in the simulated coarse-grained heat-affected zone of Ti-microalloyed steels. Int. J. Miner. Metal. Mater. 2014, 21, 878-893. [CrossRef]

10. Wan, X.L.; Wu, K.M.; Huang, G.; Wei, R. In situ observations of the formation of fine-grained mixed microstructures of acicular ferrite and bainite in the simulated coarse-grained heated-affected zone. Steel Res. Int. 2014, 85, 243-250. [CrossRef]

11. Zhu, K.; Yang, J.; Wang, R.Z.; Yang, Z.G. Effect of Mg addition on inhibiting austenite grain growth in heat affected zones of Ti-bearing low carbon steels. J. Iron Steel Res. Int. 2011, 18, 60-64. [CrossRef]

12. Xu, L.Y.; Yang, J.; Wang, R.Z.; Wang, Y.N.; Wang, W.L. Effect of Mg content on the microstructure and toughness of heat-affected zone of steel plate after high heat input welding. Metall. Mater. Trans. A 2016, 47, 3354-3364. [CrossRef]

13. KiviÖ, M.; Holappa, L. Addition of titanium oxide inclusions into liquid steel to control nonmetallic inclusions. Metall. Mater. Trans. B 2012, 43, 233-240. [CrossRef]

14. Zhang, L.F. Nucleation, growth, transport, and entrapment of inclusions during steel casting. JOM 2013, 65, 1138-1144. [CrossRef]

15. Chai, F.; Yang, C.F.; Su, H.; Zhang, Y.Q.; Xu, Z. Effect of magnesium on inclusion formation in Ti-killed steel and microstructural evolution in welding induced coarse-grain heat affected zone. J. Iron Steel Res. Int. 2009, 16, 69-74. [CrossRef]

16. Sakata, K.; Suito, H. Grain-growth-inhibiting effects of primary inclusion particles of $\mathrm{ZrO} 2$ and $\mathrm{MgO}$ in Fe-10 mass pct Ni alloy. Metall. Mater. Trans. A 2000, 31, 1213-1223. [CrossRef]

17. Holappa, L.; Hämäläinen, M.; Liukkonen, M.; Lind, M. Thermodynamic examination of inclusion modification and precipitation from calcium treatment to solidified steel. Ironmak. Steelmak. 2003, 30, 111-115. [CrossRef]

18. Kimura, S.; Nakajima, K.; Mizoguchi, S. Behavior of alumina-magnesia complex inclusions and magnesia inclusions on the surface of molten low-carbon steels. Mater. Trans. A 2001, 32, 79-85. [CrossRef]

19. Kim, H.S.; Lee, H.G.; Oh, K.S. Evolution of size, composition, and morphology of primary and secondary inclusions in $\mathrm{Si} / \mathrm{Mn}$ and $\mathrm{Si} / \mathrm{Mn} / \mathrm{Ti}$ deoxidized steels. ISIJ Int. 2002, 42, 1404-1411. [CrossRef]

20. Hou, Y.; Zheng, W.; Wu, Z.; Li, G.; Moelans, N.; Guo, M.; Khan, B.S. Study of Mn absorption by complex oxide inclusions in Al-Ti-Mg killed steels. Acta Mater. 2016, 118, 8-16. [CrossRef]

21. Lifshitz, I.M.; Slyozov, V.V. The kinetics of precipitation from supersaturated solid solutions. J. Phys. Chem. Solids 1961, 19, 35-50. [CrossRef]

22. Wagner, C. Theorie der Alterung von Niederschägen durch Umlösen. Z. Elektrochem. 1961, 65, 581-594.

23. Gourgues, A.F.; Flower, H.M.; Lindley, T.C. Electron backscattering diffraction study of acicular ferrite, bainite, and martensite steel microstructure. Mater. Sci. Technol. 2000, 16, 26-40. [CrossRef]

24. Byun, J.S.; Shim, J.H.; Cho, Y.W.; Lee, D.N. Non-metallic inclusion and intragranular nucleation of ferrite in Ti-killed C-Mn steel. Acta Mater. 2003, 51, 1593-1606. [CrossRef]

25. Shim, J.H.; Cho, Y.W.; Chung, S.H.; Shim, J.D.; Lee, D.N. Nucleation of intragranular ferrite at $\mathrm{Ti}_{2} \mathrm{O}_{3}$ particle in low carbon steel. Acta Mater. 1999, 47, 2751-2760. [CrossRef]

26. Shim, J.H.; Oh, Y.J.; Suh, J.Y.; Cho, Y.W.; Shim, J.D.; Byun, J.S.; Lee, D.N. Ferrite nucleation potency of non-metallic inclusions in medium carbon steels. Acta Mater. 2001, 49, 2115-2122. [CrossRef]

27. Mabuchi, H.; Uemore, R.; Fujioka, M. The role of Mn depletion in intra-granular ferrite transformation in the heat affected zone of welded joints with large heat input in structural steels. ISIJ Int. 1996, 36, 1406-1412. [CrossRef]

28. Zhang, Z.; Farrar, R.A. Role of non-metallic inclusions in formation of acicular ferrite in low alloy weld metals. Mater. Sci. Technol. 1996, 12, 237-260. [CrossRef]

29. Enomoto, M. Nucleation of phase transformation at intragranular inclusions in steel. Metab. Mater. 1998, 4, 115-123. [CrossRef]

30. Zhang, S.; Hattori, N.; Enomoto, M.; Tarui, T. Ferrite nucleation at ceramic/austenite interfaces. ISIJ Int. 1996, 36, 1301-1309. [CrossRef]

31. Lee, T.K.; Kim, H.J.; Kang, B.Y.; Hwang, S.K. Effect of inclusion size on the nucleation of acicular ferrite in welds. ISIJ Int. 2000, 40, 1260-1268. [CrossRef]

32. Moon, J.; Lee, C.; Uhm, S.; Lee, J. Coarsening kinetics of TiN particle in a low alloyed steel in weld HAZ: considering critical particle size. Acta Mater. 2006, 54, 1053-1061. [CrossRef] 
33. Zener, C. Theory of growth of spherical precipitates from solid solution. J. Appl. Phys. 1949, 20, 950-953. [CrossRef]

34. Zhu, K.; Yang, Z. Effect of magnesium on the austenite grain growth of the heat-affected zone in low-carbon high-strength steels. Metall. Mater. Trans. A 2011, 42, 2207-2213. [CrossRef]

35. Fuentes, M.D.; Mendia, A.I.; Gutiérrez, I. Analysis of different acicular ferrite microstructures in low-carbon steels by electron backscattered diffraction. Study of their toughness behavior. Metall. Mater. Trans. A 2003, 34, 2505-2516. [CrossRef]

36. Kim, Y.M.; Lee, H.; Kim, N.J. Transformation behavior and microstructural characteristics of acicular ferrite in linepipe steels. Mater. Sci. Eng. A 2008, 478, 361-370. [CrossRef]

37. Sung, H.K.; Sang, S.Y.; Cha, W.; Oh, K.; Lee, S.; Kim, N.J. Effects of acicular ferrite on charpy impact properties in heat affected zones of oxide-containing API X80 linepipe steels. Mater. Sci. Eng. A 2011, 528, 3350-3357. [CrossRef]

(C) 2018 by the authors. Licensee MDPI, Basel, Switzerland. This article is an open access article distributed under the terms and conditions of the Creative Commons Attribution (CC BY) license (http:/ / creativecommons.org/licenses/by/4.0/). 